\title{
BMJ Open E-cigarette marketing in UK stores: an observational audit and retailers' views
}

\author{
D Eadie, ${ }^{1}$ M Stead, ${ }^{1}$ A M MacKintosh, ${ }^{1}$ L MacDonald, ${ }^{1}$ R Purves, ${ }^{1} \mathrm{~J}$ Pearce,${ }^{2}$ \\ C Tisch, ${ }^{2}$ W van der Sluijis, ${ }^{3}$ A Amos, ${ }^{4}$ A MacGregor, ${ }^{5}$ S Haw ${ }^{6}$
}

To cite: Eadie D, Stead M, MacKintosh AM, et al. E-cigarette marketing in UK stores: an observational audit and retailers' views. BMJ Open 2015;5:e008547. doi:10.1136/bmjopen-2015008547

- Prepublication history for this paper is available online. To view these files please visit the journal online (http://dx.doi.org/10.1136/ bmjopen-2015-008547).

Received 20 April 2015 Revised 16 July 2015 Accepted 4 August 2015

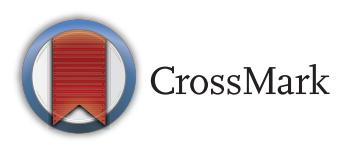

${ }^{1}$ Institute for Social Marketing, School of Health Sciences, University of Stirling, Stirling, UK ${ }^{2}$ Centre for Research on Environment Society and Health, School of

GeoSciences, University of Edinburgh, Edinburgh, UK ${ }^{3}$ Child and Adolescent Health Research Unit, University of St Andrews, St Andrews, UK

${ }^{4}$ Centre for Population Health Sciences, School of

Molecular Genetic and

Population Health Sciences,

University of Edinburgh,

Edinburgh, UK

${ }^{5}$ ScotCen Social Research, Edinburgh, UK

${ }^{6}$ School of Health Sciences, University of Stirling, Stirling, UK

Correspondence to Dr D Eadie;

douglas.eadie@stir.ac.uk

\section{ABSTRACT}

Objectives: To explore how e-cigarettes are being promoted at point of sale in the UK and how retailers perceive market trends.

Setting: Fixed retail outlets subject to a ban on the display of tobacco products.

Participants: Observational audit of all stores selling tobacco products $(n=96)$ in 4 Scottish communities, conducted over 2 waves 12 months apart (2013-2014), and qualitative interviews with small retailers $(n=25)$ in 4 matched communities.

\section{Primary and secondary outcome measures:}

The audit measured e-cigarette display characteristics, advertising materials and proximity to other products, and differences by area-level disadvantage. Interviews explored retailers' perceptions of e-cigarette market opportunities and risks, and customer responses.

Results: The number of e-cigarette point-of-sale display units and number of brands displayed increased between waves. E-cigarettes were displayed close to products of interest to children in $36 \%$ of stores. Stores in more affluent areas were less likely to have external e-cigarette advertising than those in deprived areas. Although e-cigarettes delivered high profit margins, retailers were confused by the diversity of brands and products, and uncertain of the sector's viability. Some customers were perceived to purchase e-cigarettes as cessation aids, and others, particularly low-income smokers, as a cheaper adjunct to conventional tobacco.

Conclusions: E-cigarette point-of-sale displays and number of brands displayed increased over 12 months, a potential cause for concern given their lack of regulation. Further scrutiny is needed of the content and effects of such advertising, and the potentially normalising effects of placing e-cigarettes next to products of interest to children.

\section{INTRODUCTION}

The global e-cigarette market was estimated in 2014 at around $£ 1.8$ billion (€2.3 billion; $\$ 3$ billion), ${ }^{1}$ and in the UK, is expected to be worth around $£ 340$ million by $2015 .^{2}$ Recent years have seen rapid increases in the awareness and use of e-cigarettes in several highincome countries, including the USA and

\section{Strengths and limitations of this study}

- This is the first study to combine retail audit and interview data to not only explore how ecigarettes are being promoted and trends in their availability in the UK retail setting, but also to provide a unique perspective on retailers' views on the long-term viability of the products, and how their customers are responding to the range of product variants on offer.

- The study provides a timely opportunity to examine the impact of the proliferation of $e$ cigarettes in an unregulated form, in a setting where conventional tobacco products are being covered up and are becoming a less prominent feature in the retail context.

- The study provides insight into a number of contrasting communities in terms of deprivation and urbanisation, but does not seek to offer a representative picture of all retail outlets selling ecigarettes in Scotland.

- The sample derives from all retailers selling tobacco in the study communities, so it may not represent the full range of outlets selling $e-$ cigarettes, most notably specialist e-cigarette outlets and community pharmacies.

the UK, ${ }^{13}$ and in the number of brands on the market. ${ }^{5}$ However, business commentators suggest that this growth will slow in the future as the market matures and consolidates, and successful small companies are bought over by larger corporations led by the pharmaceutical and tobacco sectors. ${ }^{6} 7$

The UK provides an interesting context in which to explore the nature and extent of ecigarette marketing in local high street stores. In contrast to tobacco products, there is currently minimal regulation in the UK on e-cigarette advertising and no minimum age of sale. ${ }^{8}$ There is a growing trend towards selling e-cigarettes online and through specialist e-cigarette or 'vaping' stores. Despite this, high street stores, particularly grocery/ convenience stores and confectioners/tobacconists/newsagents (CTNs), are still an important part of the e-cigarette retail 
landscape-UK sales of e-cigarettes through grocery stores (not including specialist stores or online sales) were worth $£ 125.4$ million in $2014 .^{7}$ E-cigarette producers have been described as keen to harness traditional local grocery store channels, ${ }^{7}$ where staff often have good relationships with customers and can educate them about these new products. High street retailers can perform a dual marketing role, on the one hand advising on product selection, and on the other gathering feedback on customer preferences.

In short, retail stores are a key source of exposure to ecigarette marketing and a potentially valuable source of insight into consumer trends and attitudes. Whether ecigarettes are regarded as a positive development in terms of smoking cessation and harm reduction, or as a cause for concern (eg, the potential to renormalise tobacco smoking has been discussed ${ }^{9-11}$ ), it is important to understand more about how they are being sold, promoted and purchased in this key setting. Given the much higher rates of tobacco smoking and lower rates of quitting in disadvantaged communities in the $\mathrm{UK},{ }^{12}{ }^{13}$ it is also important to understand whether ecigarette marketing exposure and perceptions of customers' motives for purchasing them differ between advantaged and disadvantaged communities. In view of this, the current study sought to:

A. Assess changes in the marketing of e-cigarettes over two waves 12 months apart;

B. Assess whether marketing of e-cigarettes differs by level of disadvantage;

C. Explore retailers' attitudes towards selling ecigarettes, including their views on the market's viability and their perceptions of customer motives for purchase.

\section{METHODS}

The data presented here were collected as part of a longitudinal study designed to evaluate the impacts of the legislation prohibiting point of sale (POS) tobacco advertising by tobacco retailers in Scotland. ${ }^{6}$ For this paper, data were collected from an observational audit of retail outlets in four communities in Scotland over two waves, in February/April 2013 and 2014, prior to the staged introduction of the legislation, and from follow-up interviews conducted with a panel of small independent retailers from four matching communities, between June and August 2014. The prohibition of tobacco displays was introduced in two stages: large and small shops in Scotland were required to remove all tobacco displays by 29 April 2013 and 6 April 2014, respectively.

\section{Observational audit}

This comprised a discreet audit of all geographically fixed retail outlets selling tobacco in four communities in Scotland $(n=96)$. Each community was defined as the catchment area of one of four secondary schools.
The schools were selected to reflect different levels of urbanisation and social deprivation, assessed using the Scottish Index of Multiple Deprivation (SIMD) scores (see Haw et $a l^{14}$ for fuller description). Six categories of retail outlets were included: supermarkets, CTNs, grocery/convenience stores, petrol station/garage forecourt stores, off-licences (liquor stores) and fast food/ take-away outlets. In combination, these represented the majority of tobacco retail outlets in the study communities, with only mobile vans and illicit tobacco not included. The sample for each wave was identified from the Scottish Tobacco Register (http://www.tobacco registerscotland.org), followed by field inspections of all streets in the communities to verify coded retailers and identify any unregistered retailers.

The observations were conducted by a team of four observers working in pairs, with a field visit of 1-2 days in each study community at each wave. Data collection was facilitated by making a token purchase to allow close observation of the tobacco counter and the use of memory aids and devices, such as the use of mobile phones to record numeric data. Audit protocols were completed away from the retail sites immediately after each observation, with observers comparing notes to verify key characteristics. Where inconsistencies or gaps emerged, these were addressed by an immediate follow-up visit to the study outlet.

Measures were taken, at both waves, of the frequency and range of e-cigarette brands displayed in purposedesigned units, and the frequency of external signage for e-cigarette products. In addition, measures were taken at wave 2, of frequency of e-cigarette brands stocked, frequency of in-store marketing for e-cigarettes and proximity of e-cigarettes to youth-related products. E-cigarettes were classed as being in close proximity to youth-related products (ie, products considered by the research team to be of potential interest to young people) if they were recorded as being displayed immediately adjacent to one or more of the following: confectionery, collectible cards (eg, for football teams), mints and gums, toys/stationery, cakes, crisps/snacks, soft drinks, magazines/comics or CDs/DVDs.

Data were analysed using IBM SPSS V.21, and descriptive statistics were generated for each wave. An indicator of the level of deprivation was obtained by linking the postcode of each retail outlet with the $\operatorname{SIMD}^{15}$ and grouped by SIMD quintile. Owing to the small number of outlets in the sample, SIMD quintiles had to be combined for analyses. Bivariate analysis, using the $\chi^{2}$ test, was undertaken to compare measures of stores in the most deprived areas (SIMD quintiles 1 and 2) with those in more affluent areas (SIMD quintiles 3,4 and 5). At both waves, prevalence of purpose-designed e-cigarette displays and of any external e-cigarette advertising was examined by deprivation level. At wave 2, prevalence of stores selling e-cigarettes and of stores displaying e-cigarettes immediately adjacent to youth-related products was also examined by deprivation level. 
The McNemar test was used to test for differences, from waves 1 to 2 , in the proportions of stores displaying e-cigarettes and having external advertising for e-cigarettes. Paired t tests were used to test for differences, between waves, in the mean number of brands displayed in stores and advertised externally.

\section{Retailer interviews}

Interviews were conducted with a sample of retail proprietors in matched communities $(n=25)$. The primary focus of the interviews was to examine independent retailers' response to the ban on POS display of tobacco products, which also provided an opportunity to explore retailers' experiences of the e-cigarette category. Matched communities were used to avoid the risk of the interviews confounding the results of the main study, and were selected using the same criteria. ${ }^{14}$

Retailers were recruited using a structured protocol to represent five small retail categories: 10 grocery/convenience stores, 6 CTNs, 5 off-licences, 3 petrol station/ garage shops and 1 fast food/take-away outlet. Candidates who indicated an interest in participating and who matched the sample criteria were provided with a copy of the study information sheet and then recontacted to answer any questions, to provide written consent and to set up a suitable time for interview. All participants were offered a small financial incentive for taking part. Data were collected by three researchers using a semistructured protocol administered face-to-face in-store during business hours; one interview was conducted by telephone. Each interview lasted 20-30 min and collected data on the commercial viability of selling e-cigarettes both now and in the future, the rationale for stocking particular e-cigarette brands, and customer response to e-cigarettes, their motives for trial and patterns of use. Field visits also provided an opportunity to collect audit data, marketing materials and photographic records of tobacco and e-cigarette displays. With participants' consent, interviews were recorded on audio and transcribed for thematic analysis. Analysis of full transcripts was led by the lead researcher and a set of themes based on the core questions and topic areas was agreed at the outset. The reliability of these themes was then reassessed by a process of familiarisation with the transcript texts, and crossexamination. Discussions between researchers responsible for undertaking the interviews enabled identification of emerging themes and resolution of interpretive difference. These analyses allowed the investigation team to identify patterns across the data as a whole. Given the relatively small sample size, there was limited scope to identify subgroup variation, for example, by shop type.

\section{RESULTS}

\section{Observational audit}

Ninety-six outlets were audited at each wave (table 1). Between waves 1 and 2, three outlets were removed from
Table 1 Sample of observed retail outlets

\begin{tabular}{lcc} 
Shop categories & Wave 1 & Wave 2 \\
\hline Large supermarkets (over $\left.280 \mathrm{~m}^{2}\right)$ & 9 & 10 \\
Small shops $\left(280 \mathrm{~m}^{2}\right.$ or under) & & \\
$\quad$ Grocery/convenience stores & 54 & 54 \\
CTNs & 16 & 16 \\
Petrol station/garage forecourt shops & 10 & 10 \\
Off-licences & 4 & 3 \\
Fast food/take-away outlets & 3 & 3 \\
Total & 96 & 96 \\
\hline CTNs, confectioners/tobacconists/newsagents.
\end{tabular}

the sample (two outlets ceased trading and one ceased selling tobacco), and three new outlets were added (two new outlets opened and one began stocking tobacco products).

Two measures provided an assessment of changes in ecigarette marketing between waves 1 and 2: the number of outlets with purpose-designed display units for ecigarettes, and the amount of external advertising for ecigarettes on shopfronts (see table 2).

The number of outlets with purpose-designed display units increased from $21 \% \quad(\mathrm{n}=20)$ to $49 \% \quad(\mathrm{n}=47)$ over the two waves $(p<0.001)$. At both stages, free-stand towers were the most popular type of display design. These were typically positioned on shop counters immediately adjacent to the service point. Display units for E-Lites and Nicolites were the most common at wave 1, with four other brands achieving similar prominence by wave 2: SkyCig, OK, 10 Motives and Njoy. The mean number of brands displayed, per outlet, increased from 0.21 at wave 1 to 1.5 at wave $2(p<0.001)$.

The number of outlets with external advertising for ecigarettes remained constant at $10(10 \%)$ at both waves, although the range of different brands advertised externally extended from 3 at wave 1 to 9 at wave 2 . At wave 1 , external advertising was limited to single brands. By wave 2, multiple brands were advertised, with a maximum of four brands advertised at any one outlet. However, the mean number of brands externally advertised per outlet did not differ significantly between waves 1 (0.10, 0.31) and $2(0.2,0.66)$.

Prevalence of purpose-designed e-cigarette displays did not differ significantly, by deprivation level, at either wave 1 or 2 . At wave 1 , prevalence of external e-cigarette advertising was more prevalent at stores in more deprived SIMD areas (quintiles 1 and 2): only 2\% ( $n=1)$ of the outlets in less deprived quintiles had external e-cigarette advertising compared with $18 \% \quad(n=9)$ in more deprived quintiles $(p<0.01)$. However, given the small cell sizes, caution has to be exercised when interpreting these findings. At wave 2, prevalence of external e-cigarette advertising did not differ significantly by deprivation level.

The wave 2 audit also included additional measures of the number of e-cigarette brands stocked, types of 
Table 2 E-cigarette displays and shop fascia advertising, 12-month comparison

\begin{tabular}{|c|c|c|}
\hline & $\begin{array}{l}\text { Wave } 1 \\
(n=96)\end{array}$ & $\begin{array}{l}\text { Wave } 2 \\
(n=96)\end{array}$ \\
\hline \multicolumn{3}{|l|}{ Internal e-cigarette displays } \\
\hline $\begin{array}{l}\text { Number of outlets with } \\
\text { purpose-designed displays* }\end{array}$ & $20(21 \%)$ & 47 (49\%) \\
\hline \multicolumn{3}{|l|}{ Display unit type } \\
\hline Tower & $7(7 \%)$ & $29(30 \%)$ \\
\hline Tray & $1(1 \%)$ & $19(20 \%)$ \\
\hline Hanger & $5(5 \%)$ & $3(3 \%)$ \\
\hline Other & $0(0 \%)$ & $2(2 \%)$ \\
\hline Unspecified & $7(7 \%)$ & $0(0 \%)$ \\
\hline \multicolumn{3}{|l|}{ Brand } \\
\hline Elites & $9(9 \%)$ & $21(22 \%)$ \\
\hline Nicolites & $8(8 \%)$ & $22(23 \%)$ \\
\hline SkyCig & $0(0 \%)$ & $14(15 \%)$ \\
\hline OK & $0(0 \%)$ & $11(11 \%)$ \\
\hline 10 Motives & $1(1 \%)$ & $17(18 \%)$ \\
\hline Njoy & $0(0 \%)$ & $12(13 \%)$ \\
\hline VIP & $0(0 \%)$ & $5(5 \%)$ \\
\hline Vype & $0(0 \%)$ & $4(4 \%)$ \\
\hline Vivid & $0(0 \%)$ & $3(3 \%)$ \\
\hline Multicig & $0(0 \%)$ & $3(3 \%)$ \\
\hline Diamond Mist & $0(0 \%)$ & $2(2 \%)$ \\
\hline Impulse & $1(1 \%)$ & $2(2 \%)$ \\
\hline i-Breathe & $0(0 \%)$ & $2(2 \%)$ \\
\hline Collins & $0(0 \%)$ & $2(2 \%)$ \\
\hline Bull & $0(0 \%)$ & $2(2 \%)$ \\
\hline Unspecified & $1(1 \%)$ & $0(0 \%)$ \\
\hline $\begin{array}{l}\text { Mean number of brands } \\
\text { displayed } \dagger\end{array}$ & 0.21 & 1.50 \\
\hline SD & 0.41 & 1.31 \\
\hline \multicolumn{3}{|c|}{ External advertising for e-cigarette brands } \\
\hline Number of outlets with any & $10(10 \%)$ & $10(10 \%)$ \\
\hline \multicolumn{3}{|l|}{ e-cigarette ads on shop fasciał } \\
\hline \multicolumn{3}{|l|}{ Brand advertised } \\
\hline Elites & $8(8 \%)$ & $3(3 \%)$ \\
\hline SkyCig & $1(1 \%)$ & $3(3 \%)$ \\
\hline VIP & $0(0 \%)$ & $2(2 \%)$ \\
\hline OK & $0(0 \%)$ & $2(2 \%)$ \\
\hline A-cigarettes & $1(1 \%)$ & $1(1 \%)$ \\
\hline E-liquid & $0(0 \%)$ & $1(1 \%)$ \\
\hline Collins & $0(0 \%)$ & $1(1 \%)$ \\
\hline Diamond Mist & $0(0 \%)$ & $1(1 \%)$ \\
\hline Starlite & $0(0 \%)$ & $1(1 \%)$ \\
\hline \multicolumn{3}{|c|}{ Number of e-cigarette ads on shop fascia } \\
\hline None & $86(90 \%)$ & $86(90 \%)$ \\
\hline One brand & $10(10 \%)$ & $4(4 \%)$ \\
\hline Two brands & $0(0 \%)$ & $4(4 \%)$ \\
\hline Three brands & $0(0 \%)$ & $1(1 \%)$ \\
\hline Four brands & $0(0 \%)$ & $1(1 \%)$ \\
\hline Mean§ & 0.10 & 0.2 \\
\hline SD & 0.31 & 0.66 \\
\hline
\end{tabular}

${ }^{*}$ McNemar test for differences waves 1-2: $p<0.001$

†Paired $t$ test for differences waves 1-2: $p<0.001$.

$\ddagger$ McNemar test for differences waves 1-2: not significant, $p>0.99$. $\S$ Paired t test for differences waves 1-2: not significant, $p=0.161$.

e-cigarette promotional materials, and proximity of e-cigarettes to products of potential interest to children and young people (see table 3 ).
Table 3 E-cigarette brands stocked, types of e-cigarette promotional materials and proximity of e-cigarettes to products of potential interest to children, at wave 2

\begin{tabular}{lc}
\hline & $\begin{array}{l}\text { Wave 2 } \\
\text { (n=96) }\end{array}$ \\
\hline $\begin{array}{l}\text { Number of outlets selling e-cigarettes in } \\
\text { purpose-designed displays }\end{array}$ & $47(49 \%)$ \\
Number of outlets selling e-cigarettes not in & $27(28 \%)$ \\
purpose-designed displays & \\
Total number of outlets selling e-cigarettes & $74(77 \%)$ \\
Number of e-cigarette brands on sale in each outlet \\
None & $22(23 \%)$ \\
One brand & $34(35 \%)$ \\
Two brands & $22(23 \%)$ \\
Three brands & $10(10 \%)$ \\
Four brands & $5(5 \%)$ \\
Five brands & $2(2 \%)$ \\
Six brands & $1(1 \%)$ \\
Mean & 1.5 \\
SD & 1.31 \\
Number of outlets with any e-cigarette & $14(15 \%)$ \\
promotional materials & \\
Change mats & $6(6 \%)$ \\
Posters & $5(5 \%)$ \\
Leaflets & $3(3 \%)$ \\
Dangler ads & $2(2 \%)$ \\
Other & $1(1 \%)$
\end{tabular}

Number of outlets with e-cigarettes displayed immediately adjacent to youth-related products

$\begin{array}{ll}\text { Yes } & 35(36 \%) \\ \text { No } & 39(41 \%) \\ \text { E-cigarettes not on sale } & 22(23 \%)\end{array}$

Number of outlets stocking e-cigarettes next to

Confectionery

$20(21 \%)$

Collectible cards

$10(10 \%)$

Mints and gum

$9(9 \%)$

Toys and stationery

$4(4 \%)$

Buns and cakes

$3(3 \%)$

Frozen confection

$2(2 \%)$

Crisps and snacks

$1(1 \%)$

Soft drinks

$1(1 \%)$

Magazines and comics

$1(1 \%)$

CDs and DVDs 
Promotional material for e-cigarettes was only observed in off-licences, grocers/convenience stores and CTNs, with no promotional materials observed in supermarkets, petrol stations or fast food outlets. While all supermarkets stocked e-cigarettes, none of the fast food outlets stocked them. The 10 large supermarkets audited all sold e-cigarettes from a separate tobacco kiosk, while 2 also stocked e-cigarettes next to pharmaceutical or smoking cessation products.

At wave 2, there was no significant difference, by deprivation level, in the proportion of stores that sold ecigarettes or the proportion that displayed e-cigarettes immediately adjacent to youth-related products.

\section{Retailer interviews}

The interviews with retailers $(\mathrm{n}=25)$ in matched communities provided insight into three main aspects of e-cigarette retailing and marketing: the values and risks small retailers attached to stocking e-cigarettes; retailers' views on emerging trends and changes in the market; and retailers' perceptions of the types of customer who bought e-cigarettes and their motives for doing so.

\section{Value and risks attached to stocking e-cigarettes}

Unit profit margins from selling e-cigarettes were reported to be significantly higher than for conventional tobacco products, making it a viable product line for many retailers, even at relatively low levels of turnover. As one grocery/convenience store owner explained:

I was doing about a hundred pounds, maybe two hundred pounds a week on e-cig sales, which was very good. And that was probably making me the same sort of money I was doing selling a thousand pounds of cigarettes. There is very little profit margin in cigarettes, there is only 5\%. (Retailer, Grocery/Convenience store)

Despite these returns, retailers were often wary of stocking e-cigarettes in the absence of any clear demand for the product from customers, fearing they could be left with unsold stock. One off-licence owner commented that he would consider them if he had: 'folk in every other day asking for them', but even then would be put off by the 'considerable outlay', while another interviewee had stocked starter kits and sold two units, but customers had not returned for refills, leaving him with stock he had to return.

The diverse range of brands-"the problem with ecigarettes is that there is that many" (Retailer, Off-licence) - and lack of familiarity with the product resulted in considerable uncertainty among retailers about which brands to stock and which would prove good sellers. These concerns were further compounded by concerns about product quality and perceived poor reliability, with some retailers reporting high levels of customer complaints and returns. Some retailers sought to minimise these commercial risks by selecting what they regarded as more reputable suppliers with stronger brands and integrated marketing campaigns, who were prepared to back their products with favourable sale and return policies, free in-store materials and displays, and ongoing support from company representatives:

E-Lites were just launched, we had no advice, nothing, but the e-cig companies were there, they sent their reps around the shops. They were at the cash-and-carry [wholesale store], explained the product. There is also a lot of advertising, media advertising and that helps us decide which brand to stock. (Retailer, Grocery/ Convenience store)

The rep [for Blu] came in, and she gave us all the stock and like, sale or return,--'Whatever is away [sold], that is what we will charge you for'-she gave us about three hundred pounds worth of stock. (Retailer, CTN)

These strategies may explain the wide availability and strong presence of brands such as E-Lites and SkyCig (rebranded as Blu in Spring 2014) in the Scottish retail sector, although even among these more familiar brands there were reports of product failures and of sales representatives failing to maintain contact with shopkeepers.

While it was considered too early to reliably assess the potential for e-cigarettes to replace tobacco products, some retailers regarded e-cigarettes as a suitable product to fill the display areas about to be vacated by tobacco products from POS, with some anticipating displaying ecigarettes alongside a range of popular youth-related products:

You are allowed to keep the E-Lites. It is still a tobacco thing, but you are allowed to keep that out [ie, to continue to display e-cigarettes after the tobacco display ban comes into force]...I am going to put them [e-cigarettes] in the sundry stand. And on the main tobacco gantry I'm going to put the sweets, the jars, and then where the ecigarettes are [at the moment] I am going to try and put that slush [iced drinks] machine there. (Retailer, CTN)

\section{Observed trends in the market for e-cigarettes}

The rapid growth in the number of new e-cigarette products and brands coming onto the market place had been challenging for many small retailers; one described it as a 'minefield', with "a lot of cheap, knock-off [counterfeit] ones" (Retailer, Grocery/Convenience store).

Despite wide product availability and choice, many retailers reported that actual demand for the product, while initially high, had slowed down and in some areas stalled; a trend attributed by some retailers to customers' unwillingness to switch and to the product's perceived failure to match the properties of conventional tobacco. One grocery/convenience store owner noted that customers were mostly 'pensioners' who 'don't change' in their habits, and another commented:

People are moving back to their own cigarettes, the actual thing. They are saying it is not the same as what a cigarette is. (Retailer, Grocery/Convenience store) 
Some retailers saw the downturn in these firstgeneration products as part of a broader trend, with reports of customers now expressing an interest in second-generation refillable liquid vaping products that use new cartridge technology to deliver a diverse range of flavours and strengths: one off-licence retailer commented that 'everyone has gone onto the liquids now'.

There was a suggestion from some retailers that these second-generation products represented a step-change improvement in the product's ability to satisfy consumer needs:

You get the ones that recharge, but they didn't really take off here you know. Whereas I think the new oil ones are more realistic...I think it's more of an authentic taste maybe. (Retailer, Grocery/Convenience store)

However, the ability of small independent retailers to stock and market these more sophisticated and increasingly popular refillable brands emerged as an issue; one grocery/convenience store owner commented that 'the new ones with the oil' could only be obtained from certain distributors, and another commented on a nearby specialist shop that 'dominate[d] the market here' in liquid products.

\section{Perceived customer motives for buying e-cigarettes}

Most retailers reported that the majority of their customers who bought e-cigarettes were established smokers: "It's people who are long-term smokers, people who have been smoking for maybe ten, twenty years" (Retailer, Grocery/Convenience store). Some retailers described how the emergence of e-cigarettes as a new form of smoking had stimulated initial interest among existing smokers-"they want to try it, even if they aren't a hundred percent committed [to switching or cessation]" (Retailer, Grocery/Convenience store)—but this had not necessarily translated into sustained use.

Beyond an initial desire to experiment, the reasons that retailers perceived for customer interest in the product were more complex. Two contrasting explanations were ventured: e-cigarettes as a route to smoking cessation:

Just as an example, there are eighteen people across the road there in those houses, they all stopped smoking because of the price and they are all now using ecigarettes...(Retailer, CTN)

and e-cigarettes as a means of sustaining a smoking habit:

Sometimes, they cannae afford it [to buy tobacco], so they smoke that [e-cigarettes]. When they can afford it, they come and buy the cigarettes [ie, tobacco]. (Retailer, CTN)

It's mostly people who want to stop smoking, who can't afford to smoke, so they are trying to create a balance between their cravings and smoking, so a lot of people are using e-cigs and cigarettes. (Retailer, Grocery/ Convenience store)

Retailers perceived that e-cigarettes' better value for money and affordability were important to different degrees to both groups of customers. For those customers who were perceived to use e-cigarettes as a cessation aid or a means of cutting down, the potential cost savings appeared to be an incidental or secondary benefit to smoking e-cigarettes. While for those customers who sought to continue smoking, retailers perceived that greater affordability was an essential part of the decision to use e-cigarettes as an occasional substitute for tobacco. Retailers noted that customers who used e-cigarettes in these ways tended to be on low incomes and tended to rely on lower priced disposable products; these same smokers might also choose to switch from cigarettes to cheaper rolling tobacco to sustain their smoking habit during periods of financial hardship.

Finally, while few retailers reported much interest in ecigarettes in general among young customers, some noted that flavoured products had some appeal to this group: one grocery/convenience store owner described 'eighteen, twenty-one-year-olds' coming in to try the liquids because they were 'something cool', and another commented:

They [teenagers] don't have a particular interest in the likes of E-Lites but they do have an interest in like these wee things like these flavoured pens [shows interviewer product]...it's like a water melon flavour pen. It's a shisha pen, that's what they call it nowadays. It's just a flavour, it's a non-tobacco flavour. There is no nicotine in it. (Retailer, Grocery/Convenience store)

There appeared to be limited awareness among retailers as well as local authorities as to restrictions governing the sale of these products. One grocery/convenience store owner described enquiring about the rules on shisha pen sales to a local police officer, who was described as similarly uncertain. There was similar uncertainty regarding e-cigarette products containing nicotine, with retailers sometimes expressing divergent views on the legality of selling these products to young people:

I don't think there is a legal restriction on [selling] ecigarettes to kids. Not that I know personally. I wouldn't sell them myself morally, but not that we've had anyone asking, none of the kids have been asking. (Retailer, CTN)

We've never had any kids asking for them, but I would still assume that it's the same restrictions as tobacco. (Retailer, Garage shop).

\section{DISCUSSION}

Findings from this audit of all retailers selling tobacco products in four Scottish communities indicated that the 
number of e-cigarette brands and purpose designed displays for e-cigarettes increased between 2013 and 2014. By early 2014, around three-quarters of outlets $(n=74$, $77 \%$ ) were observed to stock at least one brand of ecigarettes. Hsu et $a l^{16}$ observed $57 \%$ of stores in a London sample selling e-cigarettes in June-July 2013. Although the communities are different, the two findings confirm that the e-cigarette market has continued to grow in the UK. Hsu $e t a l \mathrm{~s}^{16}$ study found a statistically non-significant trend towards increased availability in more deprived areas. Our study found no difference in availability between more and less deprived areas, but did observe more external advertising for e-cigarettes in stores in more deprived areas.

While our study provides insight into a number of contrasting communities in terms of deprivation and urbanisation, it does not offer a representative picture of all retail outlets selling e-cigarettes in Scotland. Similarly, the sample is derived from all retailers selling tobacco in these communities, so it is possible that it does not represent the full range of outlets selling e-cigarettes, most notably specialist e-cigarette outlets and community pharmacies (it should also be noted that e-cigarettes are promoted and sold online ${ }^{7}$ ). The relatively small sample size $(n=96)$ meant that it was not possible to analyse the data by shop type.

Despite the e-cigarette market's rapid expansion in recent years, it is not fully established in the high street small retail sector. Interviews with retailers in matched communities indicated that several had not embraced the market at all, with some unconvinced that there was customer demand, and uncertain whether current consumer interest would continue. Confusion and uncertainty over the quality, features and benefits of the many brands on offer deterred some from venturing into this new area, mindful of the risk of making an outlay on a product that might not sell. This same uncertainty has been found elsewhere, with, for example, articles in the retail sector trade press noting retailer reluctance to spend on products they do not understand, and uncertainty about how e-cigarettes might relate to or impact on sales of traditional tobacco and smoking cessation products. ${ }^{7}$ As the market matures and consolidates over the next few years, some of this uncertainty may reduce.

The interviewed retailers felt that their customers were generally still experimenting with the product and were not committed to long-term use or specific brands. Nevertheless, e-cigarettes do present an opportunity for retailers. E-cigarettes have far higher profit margins (in some cases up to $40 \%$ of sales price) than many categories, particularly cigarettes, where margins may be as low as $5-6 \%{ }^{18}$ As the market matures, and product quality improves and confidence in brands increases, it is possible that more retailers will embrace this new category. However, the implementation of the European Union's Tobacco Product's Directive in 2016 is likely to have a significant impact on what types of e-cigarettes small retailers can sell and how they can be marketed. ${ }^{8}$ E-cigarettes containing less than $20 \mathrm{mg} / \mathrm{mL}$ nicotine will come under the same marketing regulations as tobacco products. Those over $20 \mathrm{mg} / \mathrm{mL}$ will require marketing authorisation as medicines if they are still to be sold.

Industry experts suggest that, despite the growth of online and specialist vaping outlets-current estimates suggest that there are around 800 in the UK, a figure that has doubled in a single year ${ }^{5}$-high street grocery channels will continue to be an important distribution route for e-cigarette brands that offer 'alternatives to tobacco', with pharmacies potentially focusing on more 'quitting-focused' brands. ${ }^{7}$ It is also suggested that second-generation and third-generation vaping products may migrate into mainstream retail channels, especially if staff are better educated about the products, and able to explain their different requirements and accessories to customers. ${ }^{7}$

Retailers' perspectives in this study on customers' responses to e-cigarettes suggested that their consumers had a range of motives for purchase. There was clearly a curiosity interest among some customers, but this did not necessarily convert into regular purchase and use. Retailers perceived that some customers tried ecigarettes out of a desire to give up or to replace smoking, but that others, particularly those from disadvantaged backgrounds, viewed e-cigarettes as a substitute product to be used instead of tobacco at times when they could not afford their usual cigarettes. A Canadian study of current smokers' reasons for interest in ecigarettes found a similar range of motives, including smoking cessation, as a replacement for cigarettes, as a cheap alternative to cigarettes and for when users did not want to or could not smoke tobacco in public. ${ }^{19}$

Regardless of the future of the e-cigarette, be it as an effective cessation tool or potential contributor to health harm, in the immediate term this study flags up several areas worthy of more detailed investigation. E-cigarette marketing in the form of purpose-designed displays and range of brands stocked is proliferating at the same time that in-store cigarette advertising and display has been prohibited in the UK. Given that some e-cigarette advertising borrows from the language and imagery previously used in tobacco marketing, and that some products are modelled on conventional cigarettes,${ }^{20}$ this may undermine the ban on tobacco advertising, at least until 2016, by reintroducing tobacco imagery and cues into a space where they have just been removed through the POS ban. This requires ongoing scrutiny, particularly as the covering up of tobacco products could result in ecigarettes and their marketing becoming even more visible and prominent.

A second area worthy of more detailed investigation relates to the placement of e-cigarettes in small stores. Reflecting their uncertain status-neither tobacco product nor pharmaceutical product-and relative novelty, retail outlets have not yet decided how this category should be positioned and displayed. ${ }^{7}$ In the current study, display units tended to be placed 
wherever stores had room for them, often on countertops near till points-and, consequently, in prominent positions where customer traffic flow was high, and next to products of particular interest to children and young people, such as confectionery. This may contribute to normalising e-cigarettes as a widely consumed and accepted product, and points towards the need for research to examine the content and meanings attached to the channels through which e-cigarettes are sold and the way in which e-cigarettes are marketed and displayed. ${ }^{16}$ Findings from the current study suggest limited interest in e-cigarettes among young people, although there was evidence of some variability in appeal by type of e-cigarette. Finally, while the findings from our study indicate that the majority of current e-cigarette users are adult smokers, there is an uncertainty among retailers as to rules governing the sale of e-cigarette products to minors, which would appear to point to the need for stronger guidance in this area. ${ }^{21}$

Acknowledgements The authors thank Diane Dixon, research secretary at the Institute for Social Marketing, for her support in the recruitment of the retailer panel, and Aileen Paton, research coordinator at the Institute for Social Marketing, for her help in preparing this paper.

Contributors AA, AM, AMM, DE, MS, SH, WvdS and JP were co-investigators responsible for devising the overall study design. SH was the study's principle investigator. WvdS devised the methodology for sampling study areas and selected the study communities. JP and CT mapped the study areas and identified the observational audit sample. DE, MS and AMM devised the audit design and panel study. DE, MS, LM and RP collected and interpreted the audit and panel data. DE and AMM analysed the audit data. DE and MS conceived and co-wrote the paper and AA provided contextual input. All contributed to the development of the paper.

Funding This study was supported by grant 10/3000/07 from the National Institute for Health Research.

\section{Competing interests None declared.}

Ethics approval Stirling University School of Management Research Ethics Committee.

Provenance and peer review Not commissioned; externally peer reviewed.

Data sharing statement No additional data are available.

Open Access This is an Open Access article distributed in accordance with the Creative Commons Attribution Non Commercial (CC BY-NC 4.0) license, which permits others to distribute, remix, adapt, build upon this work noncommercially, and license their derivative works on different terms, provided the original work is properly cited and the use is non-commercial. See: http:// creativecommons.org/licenses/by-nc/4.0/

\section{REFERENCES}

1. Kmietowicz Z. E-cigarettes latest: users on the up but rules tighten. BMJ 2014;349:g6444.

2. Bauld L, Angus K, de Andrade M. E-cigarette uptake and marketing -a report commissioned by Public Health England. 2014.

3. Regan AK, Promoff G, Dube SR, et al. Electronic nicotine delivery systems: adult use and awareness of the "e-cigarette" in the USA. Tob Control 2013;22:19-23.

4. Adkison SE, O'Connor RJ, Bansal-Travers M, et al. Electronic nicotine delivery systems: International Tobacco Control four-country survey. Am J Prev Med 2013;44:207-15.

5. Zhu SH, Sun JY, Bonnevie E, et al. Four hundred and sixty brands and counting: implications for product regulation. Tob Control 2014;23(Suppl 3):iii3-9.

6. Card J. The e-cigarette market is burning bright. Elite Business Magazine, 2 July 2014. http://elitebusinessmagazine.co.uk/analysis/ item/the-e-cigarette-market-is-burning-bright

7. Hegarty R. Time to go all in? Focus on e-cigarettes. The Grocer, 14 February 2015:49-52.

8. Action on Smoking and Health (ASH). ASH briefing-electronic cigarettes. 2014. http://www.ash.org.uk/files/documents/ASH_715. pdf (accessed 12 Mar 2015).

9. Fairchild AL, Bayer R, Colgrove J. The renormalization of smoking? E-cigarettes and the tobacco "Endgame". N Engl J Med 2014;370:293-5.

10. Gilmore $A B$, Hartwell G. E-cigarettes: threat or opportunity? Eur J Public Health 2014;24:532-3.

11. Abrams DB, Axéll T, Bartsch $P$, et al. Statement from specialists in nicotine science and public health policy. 2014. http://nicotinepolicy. net/documents/letters/MargaretChan.pdf (accessed 12 Mar 2015).

12. Scottish Government. Creating a tobacco-free generation-a tobacco control strategy for Scotland. Edinburgh: Scottish Government, 2013. http://www.scotland.gov.uk/Resource/0041/ 00417331.pdf (accessed 12 Mar 2015).

13. Hiscock R, Bauld L, Amos A, et al. Smoking and socioeconomic status in England: the rise of the never smoker and the disadvantaged smoker. J Public Health (Oxf) 2014;34:390-6.

14. Haw S, Amos A, Eadie D, et al. Determining the impact of smoking point of sale legislation among youth (Display) study: a protocol for an evaluation of public health policy. BMC Public Health 2014;14:251.

15. Scottish Government. Scottish Index of Multiple Deprivation 2012: a national statistics publication for Scotland. Edinburgh. http://simd scotland.gov.uk/publication-2012/ (accessed 12 Mar 2015).

16. Hsu R, Myers AE, Ribisl KM, et al. An observational study of retail availability and in-store marketing of e-cigarettes in London: potentia to undermine recent tobacco control gains? BMJ Open 2013;3: e004085.

17. Parsons T. How can your shop make a mint with e-cigarettes? Better Retailing, 30 March 2014. http://www.betterretailing.com/ can-make-mint-e-cigarettes/

18. Shanagher N. High prices, low margins: a challenge for tobacco sales. Better Retailing, 18 July 2012.

19. Czoli $\mathrm{CH}$, Hammond D, White CM. Electronic cigarettes in Canada: prevalence use and perceptions among youth and young adults. Can J Public Health 2014;105:e97-e102.

20. Andrade de M, Hastings G, Angus K, et al. The marketing of electronic cigarettes in the UK. A report for Cancer Research UK, 2013.

21. Trading Standards Institute. Youth access to $E$ cigarettes and associated products. Jane MacGregor, MacGregor Consulting Ltd for the Trading Standards Institute. A report commissioned by Public Health England, 2014. 